\title{
Factors associated with appropriate inhaler use in patients with COPD - lessons from the REAL survey [Erratum]
}

Price D, Keininger DL, Viswanad B, et al. Int J Chron Obstruct Pulmon Dis. 2018;13:695-702.

The author has advised that several changes need to be made to the paper.

Page 698, Figure 1 should be replaced by:
Page 699, Results section, Left column, Second paragraph, "Of the patients who did not feel confident, more patients reported overdosing with Genuair, Ellipta, and Respimat (33.2\%, 29.4\%, and 21.4\%, respectively)." should read "Of the patients who did not feel confident, more patients reported overdosing with Genuair, Ellipta, and Respimat (35.2\%, 29.4\%, and $21.4 \%$, respectively)."

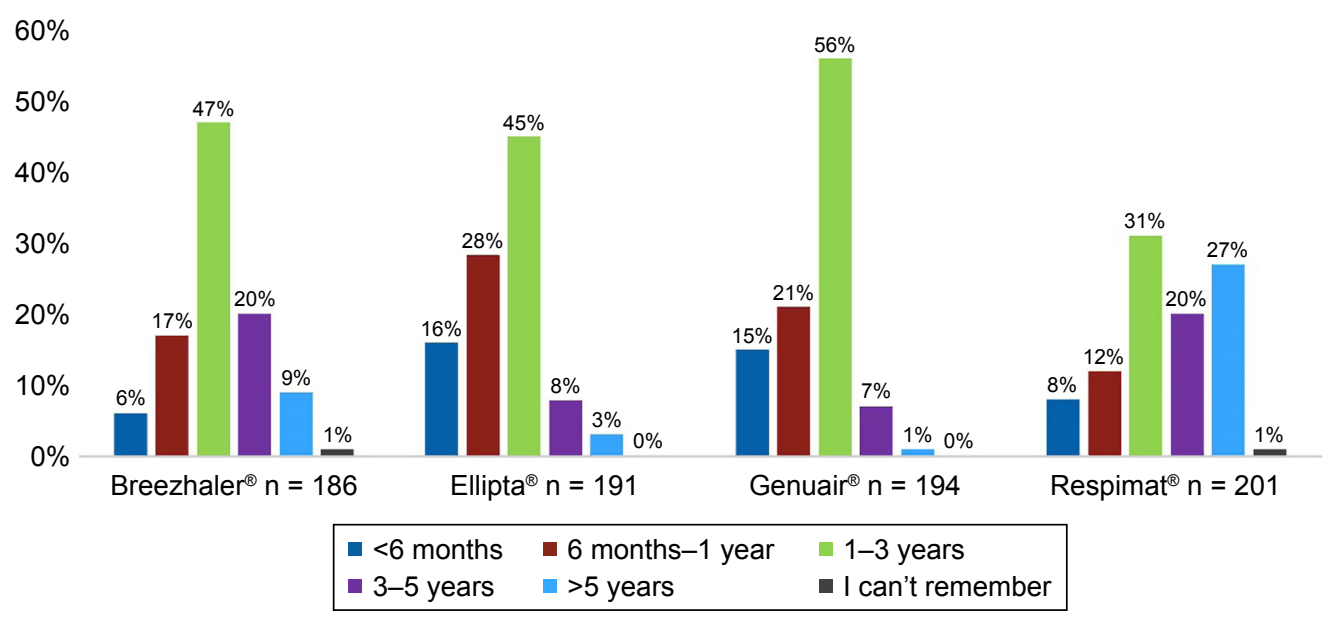

Figure I Length of use by device.

Page 700, Discussion section, Right column, Fourth paragraph, "Limitations of the survey were that measures of patient adherence were based on patient report. Additionally, there may have been possible selection bias and recall bias. The survey was also not a randomized trial and reflected real-world experience." should read "All possible efforts were made to ensure that the data received on Respimat were referring to tiotropium and not the use of short-acting bronchodilators; however this needs to be considered as a limitation of this analysis. Further limitations of the survey were that measures of patient adherence were based on patient report. Due to the nature of the trial, there might have been some recollection bias of some patients in specific countries, which indicated using the Respimat device longer than it had been approved. Additionally, there may have been possible selection bias and recall bias. The survey was also not a randomized trial and reflected real-world experience." 
Page 701, Figure 4 should be replaced by:

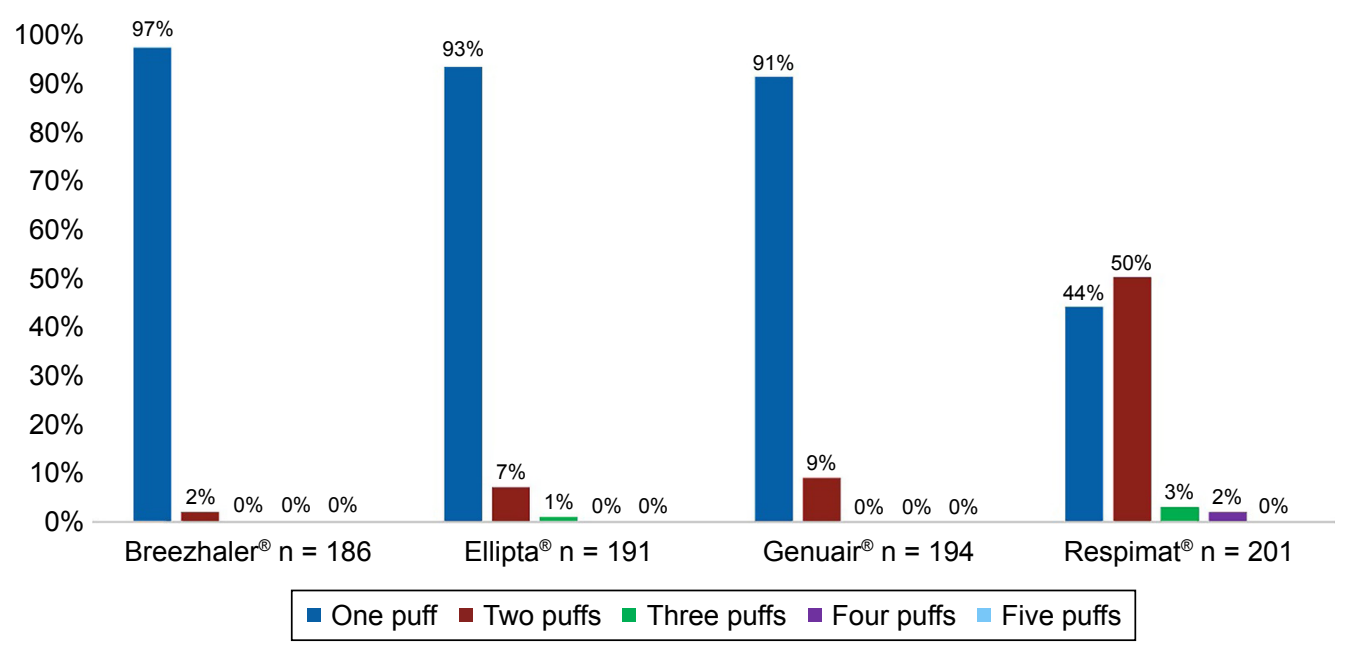

Figure 4 Proportion of device correct dosing.

\section{Publish your work in this journal}

The International Journal of COPD is an international, peer-reviewed journal of therapeutics and pharmacology focusing on concise rapid reporting of clinical studies and reviews in COPD. Special focus is given to the pathophysiological processes underlying the disease, intervention programs, patient focused education, and self management protocols.
This journal is indexed on PubMed Central, MedLine and CAS. The manuscript management system is completely online and includes a very quick and fair peer-review system, which is all easy to use. Visit http://www.dovepress.com/testimonials.php to read real quotes from published authors. 